\title{
Knowledge, attitude and practices of postgraduates, interns and nurses, on adverse drug reaction reporting in a tertiary care hospital: a comparative study
}

\author{
Mohana S. ${ }^{1}$, Narayanasamy S. ${ }^{2 *}$, Asokan B. R. ${ }^{3}$, Smita Kar ${ }^{1}$
}

\begin{abstract}
${ }^{1}$ MBBS student, ${ }^{2}$ Assistant Professor, ${ }^{3}$ Professor, Department of Pharmacology, Aarupadai Veedu Medical College, Vinayaka Mission's Research Foundation (Deemed to be University), Puducherry, India
\end{abstract}

Received: 12 January 2020

Revised: 29 January 2020

Accepted: 30 January 2020

\section{*Correspondence:}

Dr. Narayanasamy S.,

Email: narayanasamy.seenuvasan@avmc.edu.in

Copyright: ( ) the author(s), publisher and licensee Medip Academy. This is an open-access article distributed under the terms of the Creative Commons Attribution Non-Commercial License, which permits unrestricted non-commercial use, distribution, and reproduction in any medium, provided the original work is properly cited.

\begin{abstract}
Background: Pharmacovigilance is multidisciplinary field of the detection, assessment, understanding, and prevention of adverse drug reactions (ADRs). The incidences of ADRs about $95 \%$ are undocumented worldwide. However, there is a lack of information on ADR burden in developing countries due to lack of resources, infrastructure, and expertise.

Methods: A cross-sectional questionnaire-based study was conducted on 90 staff nurses 90interns and 90 postgraduates. The validated questionnaire contained items to check knowledge including 7 questions, 9 questions to analyze attitude and 5 for practices. Comparison between knowledge, attitude and practice data obtained from resident doctors and nurses was performed using Chi square test.

Results: A total of 270 healthcare professionals participated in the study. In our study the participants had good knowledge regarding the purpose of monitoring and reporting ADRs etc. The result shows that health care professionals felt reporting of ADRs is a professional obligation and all ADRs should be reported. There was no significant difference in the knowledge and attitude between interns and nurses but few questionnaires show significant variations between post graduate and staff nurse. The practice of ADR reporting was significantly higher in postgraduate compared to nurses.

Conclusions: This study concluded that post graduate, intern and staff nurse had good knowledge and positive attitude towards pharmacovigilance and ADR reporting, but unfortunately the actual practice of ADR reporting is still deficient among staff nurse and intern. This can be improved by adequate training and motivation.
\end{abstract}

Keywords: Adverse drug reactions, Health care professionals, Knowledge, Attitude and practice

\section{INTRODUCTION}

Adverse drug reactions (ADRs) of drugs are important public health problem and one of the leading causes of morbidity and mortality. As per The World Health Organization (WHO) Adverse drug reaction is harmful and unintended effect which occurs at normal doses in humans for prevention, diagnosis or therapy of disease, or for the modification of physiological functions. ${ }^{1}$ Pharmacovigilance is defined as "a multidisciplinary field which studies the science and activities relating to the detection, assessment, understanding, and prevention of adverse reactions of drugs. ${ }^{2}$ ADRs account for $0.2 \%-24 \%$ of hospital admissions and $3.7 \%$ of patients have fatal ADRs. Admissions due to ADRs in elderly patients have been reported to be higher (9\%). ADRs lead to a number 
of medical and economic consequences, like prolong hospital stay, increase the cost of treatment and risk of death. ${ }^{3}$ Agrawal et al has recorded, $8.2 \%$ are likely to develop adverse drug event out of every thousand prescription. The irrational practice of medicine leads to unnecessary financial cost to patient, health service system, increased side effects, resource constraint of patient. $^{4}$

After the thalidomide tragedy (1960s), many voluntary schemes for reporting ADR has been introduced in different countries and reporting systems have been developed. It was recognized that ADRs are one of the major causes of hospitalization. In the past decade the safety of medicinal products has become important to the manufacturers and regulatory agencies.

Some of the pharmaceutical companies were faced with high profile safety concerns resulted in withdrawals of their major drug products or even lawsuits that cost them millions of dollars and their good reputation. ${ }^{5}$

The incidences of ADRs about 95\% are undocumented worldwide. However, there is a lack of information on ADR burden in developing countries due to lack of resources, infrastructure, and expertise. Physicians and healthcare professionals have a very important role in ADRs reporting, however the number of reports received is insufficient due to inadequate knowledge about Pharmacovigilance. ${ }^{6}$ To improve the Pharmacovigilance activities in India, the Ministry of Health and Family Welfare had initiated the National Pharmacovigilance Program (NPP) on November 2004, This program is overseen by Central Drugs Standard Control Organization (CDSCO), New Delhi and National Coordination Centre, Indian Pharmacopoeia Commission, Ghaziabad. ${ }^{7,8}$

\section{Pharmacovigilance program of India}

In July 2010 the New Delhi has initiated this national wide pharmacovigilance programme initiated in July 2010 by CDCSO central drug standard control organization with help of AIIMS to monitor adverse drug reactions in national level. It was launched with a broad objective in patient safety in India. The Pharmacovigilance program functioning under the Ministry of health and Family welfare. National Coordinating Center (NCC) initiated in All India Institute of Medical Sciences (AIIMS), New Delhi. Recently NCC shifted to the Indian Pharmacopoeia Commission, Ghaziabad, Uttar Pradesh in April, 2011 under aegis of Uppsala Monitoring Center-World Health Organization (UMC-WHO). The (UMC, WHO), Sweden is maintaining the international database of ADR reports received ADRs report data from several national pharmacovigilance centers of different countries. However, still, it is estimated that only 6 to $10 \%$ of all ADRs are reported in all over the world. Although, India is one of participating in national pharmacovigilance programme. ${ }^{9}$

Pharmacovigilance is one of the developing fields in India and there exists very limited knowledge about this discipline. The Indian National Pharmacovigilance Programme lacks continuity due to lack of awareness and inadequate training about drug safety monitoring among healthcare professionals in India. Several studies were conducted in different countries to assess the knowledge, attitude, and practices (KAP) of health care professionals and reported that $82 \%$ of prescribers were aware about AE reporting systems. ${ }^{10}$

\section{METHODS}

A cross-sectional questionnaire-based study was conducted on 90 staff nurses 90interns and 90 postgraduates of our institution Aarupadai Veedu Medical College. The study period was April 2016 to September 2017. Prior approval was obtained from the Institutional Ethics Committee to conduct the study. The study included with staff nurses, interns and postgraduates. Participants were informed about the aims of the study and their consent was obtained before the study was conducted and distributed the validated questionnaire duly filled questionnaire the questionnaire contained items to check knowledge including 7 questions, 9 questions to analyze attitude and 5 for practices. In addition, space was provided to give suggestions and furnish any additional information. Participants would be explained the purpose of study and requested to complete and return the questionnaire immediately. Data were analyzed using SPSS 11 software. Comparison between KAP data obtained from resident doctors and nurses was performed using Chi square test.

\section{RESULTS}

\section{Knowledge}

All the postgraduate doctors, interns and staff nurses enrolled from different medical and surgical departments in hospital viz medicine, surgery, obstetrics, ophthalmology, and gynecology, paediatrics, otorhinolaryngology, and dermatology completed the questionnaire. Two-third of the respondents from all the categories were aware of the existing pharmacovigilance $(\mathrm{PhV})$ program in the country, but $87 \%$ of the post graduate doctors and $80 \%$ of interns and $64 \%$ nurses chose the correct definition of ADR. The post graduates interns and staff nurse had significantly $(\mathrm{p}<0.05)$ better knowledge on the elements of $\mathrm{PhV}$.

What is a serious adverse event regarding this question $85 \%$ of postgraduates selected correct answer whereas interns $88 \%$ and staff nurse $75 \%$ interns are comparatively well known regarding this $(\mathrm{p}<0.05)$. 
Definition of side effect almost postgraduate and interns and staff nurse has adequate knowledge in definition of side effect comparatively staff nurse marked correct answer about $70 \%$ than postgraduate $80 \%$ and interns $78 \%$ with $(\mathrm{p}<0.05)$.

In our study staff nurse has least knowledge regarding national ADR reporting system in India but they are fully aware about the necessity to report of ADR. Postgraduate has good knowledge regarding reporting system of ADR $88 \%$ comparatively $85 \%$ Interns and staff nurse $65 \%$ $(\mathrm{p}<0.05)$. Regarding the question for whom to report ADR the correct answer given by the post graduate $86 \%$, intern $78 \%$ and staff nurse $70 \%$. The comparison of post graduate and staff nurse $(\mathrm{p}<0.05)$. Definition of side effects correctly mentioned by the postgraduate $94 \%$, intern $87 \%$ and staff nurse $78 \%$. Comparatively post graduate and staff nurse $(\mathrm{p}<0.05)$. The ADR reporting to be done for the allopathic medicines /medical devices the correct answer given by the post graduate and interns than staff nurse comparatively $(\mathrm{p}<0.05)$.

\section{Attitude}

The necessity for ADR reporting $75 \%$ of postgraduate has given correct answer and intern about $69 \%$ and staff nurse $64 \%$ comparatively the post graduate and staff nurse the result shows significant variations $(\mathrm{p}<0.05)$. Benefit for ADR reporting, postgraduate has given correct answer $85 \%$ and intern about $80 \%$ and staff nurse $74 \%$. Comparatively the post graduate and staff nurse the result shows significant variations $(\mathrm{p}<0.05)$. Regarding the ADR reporting weather, the reporting damage professional image, postgraduate has given correct answer $85 \%$ and intern about $70 \%$ and staff nurse $74 \%$. Comparatively the post graduate, intern and staff nurse the result shows significant variations $(\mathrm{p}<0.05)$. Is there need of information on drug causing $\mathrm{ADR}$ and their risk management strategies, postgraduate has given correct answer $85 \%$ and intern about $84 \%$ and staff nurse $84 \%$ comparatively the post graduate and staff nurse the result shows significant variations $(\mathrm{p}<0.05)$. The preferred ADR reporting system like voluntary, mandatory and need base postgraduate has given correct answer $81 \%$ and intern about $72 \%$ and staff nurse $72 \%$ comparatively the post graduate and staff nurse the result shows significant variations $(p<0.05)$. The pharmaceutical products to be monitored postgraduate has given correct answer $75 \%$ and intern about $65 \%$ and staff nurse $59 \%$ comparatively the post graduate and staff nurse the result shows significant variations $(p>0.05)$. The conference or workshop on Pharmacovigilance improve the reporting postgraduate has given correct answer $81 \%$ and intern about $72 \%$ and staff nurse $72 \%$ comparatively the post graduate and staff nurse the result shows significant variations $(\mathrm{p}<0.05)$. Preferred mode to report ADR the interns has given the answer $70 \%$, postgraduate $78 \%$ and staff nurse about $67 \%$ given the correct answer $(\mathrm{p}>0.05)$. For the question regarding the reporters has worry about the legal problems $90 \%$ of post graduate shows the answer no and
$81 \%$ of intern and $78 \%$ of staff nurse mentioned the correct answer $(\mathrm{p}>0.05)$.

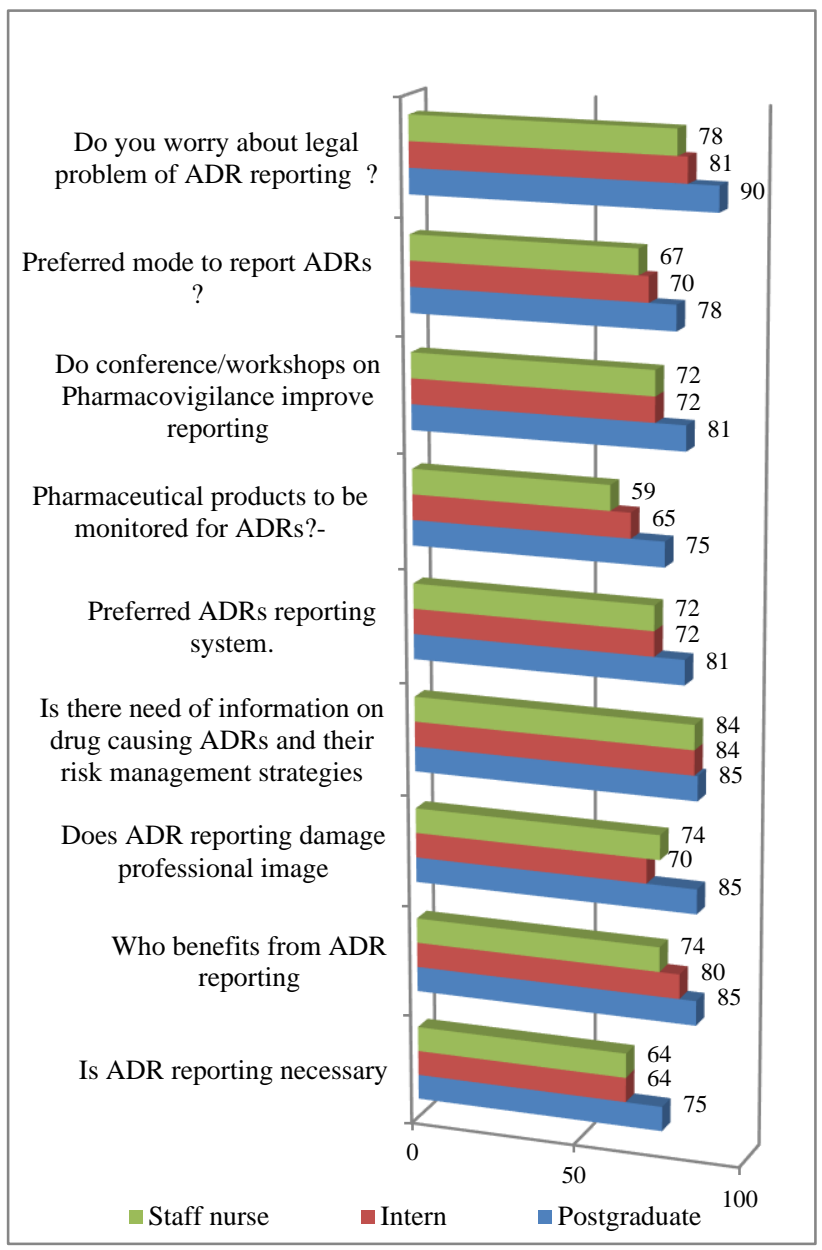

Figure 1: Attitude of staff nurses ( $n=90)$, interns $(n=90)$ and postgraduates $(n=90)$ toward monitoring and reporting ADRs.

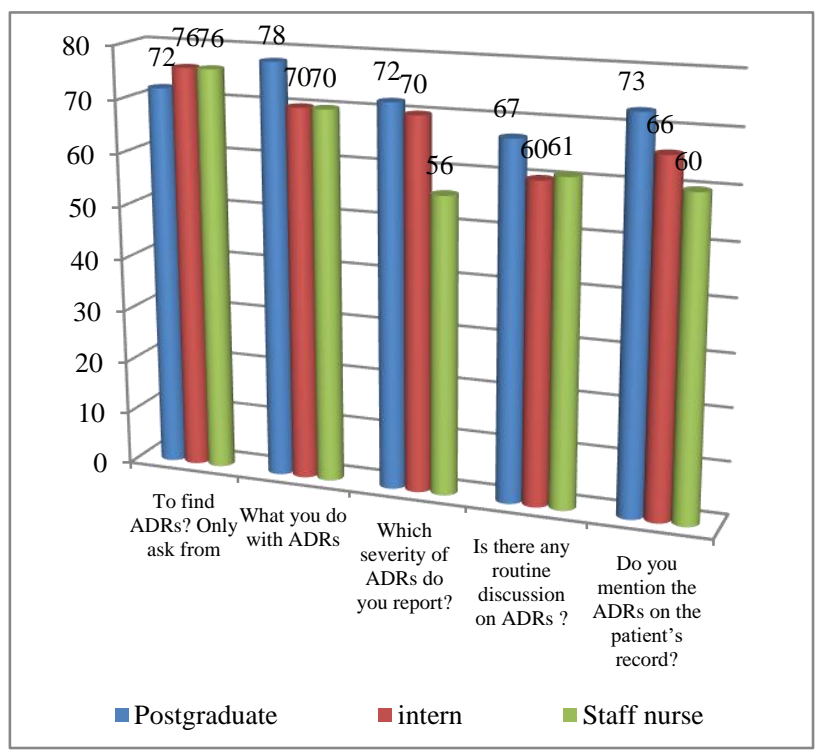

Figure 2: Practices of staff nurses $(n=90)$ interns $(n=90)$ and postgraduates $(n=90)$. 


\section{Practice}

How to find ADR weather need to ask from patients or their relatives or case sheet the staff nurse and intern shows correct answer about $76 \%$ and postgraduate given $72 \%$ ( $>>0.05$ ). Regarding the role of healthcare worker if noticed ADR, the postgraduate given the correct answer $78 \%$ and intern $70 \%$ and staff nurse $67 \%(\mathrm{p}<0.05)$. Based on the severity of ADR, which category need to report the post graduate given the answer correct $72 \%$, intern $70 \%$ and staff nurse $56 \%(\mathrm{p}<0.05)$. The need of regular discussion regarding the ADR the postgraduate said correct answer about $67 \%$, staff nurse $60 \%$ and intern $61 \%(\mathrm{p}<0.05)$. The question regarding the ADR to be mentioned in the case sheet the postgraduate given the answer $73 \%$, intern $66 \%$ and staff nurse $60 \%(\mathrm{p}<0.05)$.

\section{DISCUSSION}

ADRs are one of the most serious worldwide health problems globally, rational drug use lays down an ethical burden on the health care workers like doctors, nurse or midwives, etc. Our study aimed to evaluate the knowledge, attitude and practices of the nurse's interns and postgraduates the total participants are $270.97 \%$ of the post graduate doctors and $90 \%$ of interns and 84 nurses chose the correct definition of ADR. The post graduates interns and staff nurse had significantly $(\mathrm{p}<0.05)$ better knowledge on the elements of $\mathrm{PhV}$. Kumari et al concluded that compared to nurses and physicians have a better understanding, on attitude towards $\mathrm{PhV}$ and compared to nurses physicians attend more seminars, conferences and read various research letters. ${ }^{11}$ Comparatively in our institute the percentages of knowledge is better because $\mathrm{PhV}$ committee conducting the meeting among the faculties and staff nurse and motivating them regularly to report ADR. Postgraduate has good knowledge regarding reporting system of ADR comparatively Interns and staff nurse they are regularly follow up the patient and monitoring the treatment. Postgraduate are mentioned majority for whom to report ADR. Definition of side effects correctly mentioned by the postgraduate than intern and staff nurse. Overall the post graduate is good in knowledge of reporting the ADR. Vinoth et al concluded that reporting of ADR is a professional obligation was better known by the postgraduates than the other groups. Our research shows almost similar feedback on postgraduate in this study. ${ }^{12}$ The necessity of ADR reporting majority of postgraduate has mentioned the correct answer because have more knowledge of the disease and medicines, which helps understand and analyze the necessity of the ADRs. Regarding the benefit ADR reporting the postgraduate well known compared to intern and staff nurse $(\mathrm{p}<0.05)$. Among the healthcare professionals (HCP) the drawback of ADR reporting is weather damage professional image, in our study postgraduate has given correct answer $85 \%$ and intern and staff nurse are almost same Rehan et al concluded that resident doctors and nurses had adequate knowledge and awareness of ADR reporting and PhV. ${ }^{13}$
The doctors given majority of positive answers regarding need of information on drug causing ADR and their risk management strategies, when compared to staff nurse that shows doctors are highly exposed to various conferences, workshop and continue medical education than staff nurse.

Reporting of ADR by HCP is to be mandatory in our study postgraduate has given correct answer $81 \%$ and intern about $72 \%$ and staff nurse $72 \%$ comparatively the post graduate and staff nurse the result shows significant variations $(p<0.05)$. The question of pharmaceutical products to be monitored postgraduate has given correct answer $75 \%$ and intern about $65 \%$ and staff nurse $59 \%$. Comparatively the post graduate and staff nurse the result shows significant variations $(\mathrm{p}>0.05) .{ }^{14}$ The conference or workshop on $\mathrm{PhV}$ plays important role in reporting of ADR. The question was asked related to this, $81 \%$ postgraduate answered conference and workshop will improve the and intern about $72 \%$ and staff nurse $72 \%$. Comparatively the post graduate and staff nurse the result shows significant variations $(\mathrm{p}<0.05)$.

The study results on preferable method of reporting ADRs by consumers in future were found to be interesting. With the increasing trend of internet usage respondents preferred online reporting of ADRs as the most convenient method. Following which $81 \%$ of postgraduate mentioned the routine procedure of reporting and 19\% mentioned other mode like sending e-mail, telephone but drop box is advisable in all the aspect of documentations. Interns mentioned $76 \%$ and staff nurse mentioned $67 \%$. the question regarding the reporters has worry about the legal problems $90 \%$ of post graduate shows the answer no and $81 \%$ of intern and $78 \%$ of staff nurse mentioned the correct answer $(p>0.05)$. How to find ADR weather need to ask from patients or their relatives or case sheet the staff nurse and intern shows correct answer about $76 \%$ and postgraduate given $72 \%$. The communications among the HCPs is important for intimating to higher officials once ADR noticed to be conveyed to next level the postgraduate given the correct answer $78 \%$ and intern $70 \%$ and staff nurse $67 \%$. HCPs will ignore the mild reactions and focusing only on the moderate and severe ADR. In our survey concluded that post graduate given the answer all ADR 72\%, intern $70 \%$ and staff nurse $56 \%$. Need of regular discussion regarding the ADR the postgraduate said correct answer about $67 \%$, staff nurse $60 \%$ and intern $61 \%$. ADR to be mentioned in the case sheet the postgraduate given the answer $73 \%$, intern $66 \%$ and staff nurse.

\section{CONCLUSION}

This study concluded that postgraduate, intern and staff nurse had good knowledge and positive attitude towards pharmacovigilance and ADR reporting, but unfortunately the actual practice of ADR reporting is to be improved more among staff nurse and intern. This can be improved by adequate training and motivation. 


\section{ACKNOWLEDGEMENTS}

We would like to thank all who supported to conduct the study and participants postgraduate, intern and nurses.

Funding: No funding sources

Conflict of interest: None declared

Ethical approval: The study was approved by the Institutional Ethics Committee

\section{REFERENCES}

1. Kamal NN, Kamel EG, Mahfouz EM. Adverse drug reactions reporting, knowledge, attitude and practice of physicians towards it in El Minia University Hospitals. Int Public Health Forum. 2014;1(4)13-7.

2. Alan S, Ozturk M, Gokyildiz S, Avcibay B, Karataş Y. An evaluation of knowledge of pharmacovigilance among nurses and midwives in Turkey. Indian $\mathrm{J}$ Pharmacol. 2013;45(6):616-8.

3. Rehan HS, Vasudev K, Tripathi CD. Adverse drug reaction monitoring: knowledge, attitude and practices of medical students and prescribers. National Medical J India. 2002;15(1):24-6.

4. Mundhava S, Lalwani U, Pillai A. Prescribing Knowledge, Attitude, Practice of Interns and PostGraduates of a Tertiary Care Hospital in India. World J Pharmacy Pharma Sci. 2015;4(6):451-8.

5. Kozamernik B. Spontaneous Adverse Drug Reaction Reporting: Attitudes And Practice of Health Care Professionals and Distributors in South East European Region. Slovenian Pharmaceutical Society. 2010;61:271-80.

6. Kamal NN, Kamel EG, Mahfouz EM. Adverse drug reactions reporting, knowledge, attitude and practice of physicians towards it in El Minia University Hospitals. Int Public Health Forum. 2014;1(4):13-7.

7. Prajapati R, Dumatar C, Dikshit K, Knowledge, Attitude and Practice Regarding Adverse Drug Reaction Monitoring \& Reporting Amongst Physicians in a Tertiary Care Teaching Hospital, Ahmedabad. Indian J Applied Res. 2014;4(9)55-8.
8. Kalaiselvan V, Thota P, Singh A. Current status of adverse drug reactions monitoring centres under pharmacovigilance programme of India. Indian $\mathbf{J}$ Pharm Pract. 2014;7:19-22.

9. Upadhyaya HB, Vora MB, Jatin NGJ, Patel PB. Knowledge, attitude and practices toward pharmacovigilance and adverse drug reactions in postgraduate students of Tertiary Care Hospital in Gujarat. J Adv Pharma Tech Res. 2015;6(1):29-34.

10. Kumar P, Kumar B, Mamatha KR. Assessment Of Impact Of An Educational Intervention On The Awareness About Pharmacovigilance Among Health Care Professionals In A Tertiary Care Centre Int J Pharmacol Res. 2015;5(5):252-5.

11. Kumari S, Rishishwar P, Palaniappan S. Knowledge, Awareness and Attitude Practice among Health Care Professionals about Pharmacovigilance at Tertiary Care Hospital in Delhi Int J Pharma Res Health Sci. 2017;5(5):1862-7.

12. Vinoth K, Meenakshi B, Ezhil Ramya J. Knowledge, attitude, and practice of pharmacovigilance among health care professionals in a tertiary care hospital: a cross sectional study. Int J Basic Clin Pharmacol. 2016;5:2190-3

13. Rehan HS, Sah RK, Chopra D. Comparison of knowledge, attitude and practices of resident doctors and nurses on adverse drug reaction monitoring and reporting in a tertiary care hospital. Indian $\mathbf{J}$ Pharmacol. 2012;44:699-703.

14. Gupta P, Udupa A. Adverse drug reaction reporting and pharmacovigilance: knowledge, attitudes and perceptions amongst resident doctors. J Pharm Sci Res. 2011;3:1064-9.

Cite this article as: Mohana S, Narayanasamy S, Asokan BR, Kar S. Knowledge, attitude and practices of postgraduates, interns and nurses, on adverse drug reaction reporting in a tertiary care hospital: a comparative study. Int J Basic Clin Pharmacol 2020;9:408-12. 